\title{
Administration In Vivo of Recombinant Interleukin 2 Protects Mice against Septic Death
}

\author{
Cornelia Weyand, “ Jorg Goronzy," C. Garrison Fathman, “ and Peter O’Hanley \\ Department of Medicine, Divisions of *Immunology and ${ }^{\ddagger}$ Infectious Diseases and ${ }^{\ddagger}$ Department of Medical \\ Microbiology, Stanford University Medical Center, Stanford, California 94305
}

\begin{abstract}
Administration in vivo of recombinant interleukin 2 (rIL-2) to mice induces a polyclonal IgM response. When co-administered with a specific antigen, rIL-2 can enhance concentrations of murine IgM antibodies specific for the antigen by fivefold within 7 d of initial treatment. IgM antibodies that are induced after injection of rIL-2 include antibodies specific for $\mathbf{J 5}$, a cell wall core lipopolysaccharide (LPS) antigen that is shared by the different members of the Enterobactericeae family. We report here that mice pretreated with rIL-2 or immunized with J5 antigen $7 \mathrm{~d}$ before bacterial challenge were protected from septic death that is caused by intraperitoneal challenges with Escherichia coli. Optimal protection was provided by a combined J5 antigen and rIL-2 treatment. Acquisition of the rIL-2 and J5 antigeninduced protection against lethal bacterial infection coincided temporally with maximal serum IgM titers that also contained IgM antibodies specific for the $\mathrm{J5}$ antigen. In passive immunization experiments, the affinity-purified IgM fraction in sera of rIL-2-treated animals was identified as necessary and sufficient for protection. The IgM-depleted serum had no protective effect. The nonspecific augmentation of host-defense mechanisms without the induction of endotoxin manifestations makes rIL-2 a potential candidate to any alternative LPS-containing vaccines for the prevention of bacterial infections by gram-negative organisms since the core LPS antigen is shared among gram-negative bacteria.
\end{abstract}

\section{Introduction}

Gram-negative bacterial sepsis that is caused by microorganisms of the Enterobactericeae family is associated with high morbidity and mortality, especially in immunocompromised hosts $(1,2)$ who succumb to this infectious syndrome despite appropriate antibiotic therapy. Sequelae of gram-negative bacteremia have been related to the toxicity of endotoxin, the lipopolysaccharide (LPS) component of the outer membrane (3). There is experimental evidence that hyperimmune antisera with specificity for the LPS antigens protect animals and humans from the consequences of serious infection by gram-negative organisms (4-8). Both anti-endotoxic and anti-bacterial activities of antibodies have been considered as potential mechanisms whereby humoral immunity of the host can modulate the outcome of gram-neg-

Address reprint requests to Dr. P. O'Hanley, Stanford University Medical Center, Division of Infectious Diseases, Room S-156, Stanford, CA 94305.

Received for publication 8 September 1986 and in revised form 14 January 1987.

J. Clin. Invest.

(C) The American Society for Clinical Investigation, Inc.

$0021-9738 / 87 / 06 / 1756 / 08 \quad \$ 1.00$

Volume 79, June 1987, 1756-1763 ative septicemia. The use of endotoxin to induce protective immunity in animals and especially humans, however, has been limited by the highly toxic activity of the endotoxin molecule. Alternative approaches for immunoprophylaxis are required to allow the induction of a protective immune response to gramnegative bacteria that circumvent the major obstacle of endotoxic manifestations.

We have recently reported that recombinant interleukin 2 (rIL-2) ${ }^{1}$, when given to mice in vivo, can cause a polyclonal IgM response (9). IgM concentrations after rIL-2 treatment alone reach titers that are similar to those induced directly by immunization with specific antigens. Systemic administration of the lymphokine results in a polyclonal activation of the $T$ cell as well as the B cell compartment. It was the goal of this study to assess the potential efficacy of administering rIL-2 in vivo to protect mice from septic death by pretreatment with lymphokine injections 1 wk before infection. The protective capacity of rIL2 pretreatment was compared with the immunity induced by immunization with the LPS core J5 antigen. The J5 antigen is shared among the different members of the Enterobactericeae family. We report here that prior systemic rIL-2 administration to mice prevented septic death after intraperitoneal bacterial challenge with Escherichia coli. Combination of rIL-2 and J5 antigen therapy could further reduce mortality rates. rIL-2 pretreatment maintained its protective efficacy in mice that had been rendered refractory to subsequent bacterial challenges by previous exposure to sublethal LPS doses, which suggests that the IL-2-mediated augmentation of host defense mechanisms was distinct from induction of early phase endotoxin tolerance. Only the affinity-purified IgM fraction of serum induced after rIL-2 administration was identified as the protective serum factor in passive immunization experiments.

\section{Methods}

Animals. Female BALB/c mice were obtained from Jackson Laboratory, Bar Harbor, ME. They were used at the age of 6-8 wk and weighed between 18 and $20 \mathrm{~g}$.

Preparation and use of rIL-2. rIL-2 (batch 9A, 308B) and excipient buffer control were kindly supplied by Cetus Corp., Emeryville, CA (10). As determined by a Limulus assay, the recombinant product contained $<0.03 \mathrm{ng}$ endotoxin $/ 10^{6} \mathrm{U}$ rIL-2. This amount of LPS in the recombinant product has been determined in our laboratories to be too small to induce bromelin plaques in spleen cells. For all experiments, rIL-2 and excipient buffer control were diluted in RPMI 1640 medium, supplemented with $2 \%$ normal mouse serum. All batches were tested for their growth-supporting activities of the IL-2-dependent cell line HT2 in a biological assay before they were used for in vivo experiments.

Antigen and immunizations. E. coli $\mathrm{J} 5$ antigen was purchased from List Biological Laboratories, Campbell, CA. The LPS was isolated from

1. Abbreviations used in this paper: CFU, colony-forming units; rIL-2, recombinant IL-2. 
E. coli J5 (mutant of 0111:B4) by a modification of the method of Galanos et al. (11). BALB/c mice were immunized subcutaneously with $50 \mu \mathrm{g}$ $\mathrm{J} 5$ antigen in an aqueous solution. Secondary responses were induced by rechallenging at day 14 . Sera were collected before and $7 \mathrm{~d}$ after each immunization to determine humoral responses. One group of mice was treated with three daily doses of rIL-2 (5,000 U/injection) intraperitoneally (total dose 45,000 $\mathrm{U}$ ) in the $3 \mathrm{~d}$ after the primary and secondary immunization with $\mathrm{J} 5$. This dose has been previously demonstrated to provide maximal IgM polyclonal induction (9). Another group was not immunized with $\mathrm{J} 5$ antigen but was treated with rIL-2 according to this described protocol. Control mice received excipient control buffer instead of rIL-2. Mice were challenged with $E$. coli on day 7 of the primary response that was also $7 \mathrm{~d}$ after the initiation of the rIL-2 treatment (Table I).

Bacteria. E. coli strain $\mathrm{J} 96\left(04: \mathrm{K} 6: \mathrm{H}^{+}\right)$was used for challenge studies. It had been isolated from a patient with pyelonephritis. J96 is hemolytic, colicin V-positive, and resistant to the bactericidal activity of normal serum (12). Stock cultures were stored at $-70^{\circ} \mathrm{C}$ in Luria broth with $50 \%$ glycerol. For bacterial challenge studies, stock culture was inoculated onto trypticase soy agar plates and incubated at $37^{\circ} \mathrm{C}$ for $20 \mathrm{~h}$. The 20 $\mathrm{h}$ cultures were harvested into normal saline and the number of colonyforming units (CFU) was determined from the optical density by using standard growth curves. Standard growth curves were constructed by comparing the optical density of a bacterial suspension in saline at 600 $\mathrm{nm}$ ( $1 \mathrm{~cm}$ light path) with the number of CFU as determined by a standard agar pour technique. The bacterial solutions were calibrated to designated CFU per milliliter and kept on ice until injected intraperitoneally into mice.

Bacterial challenge experiments. Mice were challenged with an intraperitoneal injection of $E$. coli through a 27-gauge needle. To determine a lethal dose-response curve, mice received increasing doses of J96 in 1 $\mathrm{ml}$ inoculum. Mice were observed at 2-4-h intervals for the first day after infection, and then at 6-h intervals until the experiment was terminated after $5 \mathrm{~d}$. Results from these studies provided a basis to challenge mice with a designated lethal dose. Mice that were immunized with J5 antigen and/or treated with rIL-2 were challenged at day 7 after the immunization or the initiation of the treatment with rIL-2 and observed for survival as described. In some experiments, mice were infected with sublethal doses to induce early phase LPS tolerance and then were challenged with twice the $100 \%$ lethal dose $\left(\mathrm{LD}_{100}\right)$ after $24 \mathrm{~h}$.

Table I. Immunization and Treatment Protocol and Bacterial Challenge Schedule

\begin{tabular}{|c|c|c|c|}
\hline Group & $\begin{array}{l}\text { Immunization } \\
\text { on day } 1\end{array}$ & Treatment on days $1-3$ & $\begin{array}{l}\text { Serum collection or } \\
\text { bacterial challenge }\end{array}$ \\
\hline 1 & - & $\begin{array}{l}\text { Three daily excipient } \\
\text { buffer doses }\end{array}$ & Day 7 \\
\hline 2 & - & $\begin{array}{l}\text { Three daily } 5,000 \mathrm{U} \\
\text { rIL-2 doses }\end{array}$ & Day 7 \\
\hline 3 & $50 \mu$ g s.c. J5 & $\begin{array}{l}\text { Three daily excipient } \\
\text { buffer doses }\end{array}$ & Day 7 \\
\hline 4 & $50 \mu \mathrm{g}$ s.c. J5 & $\begin{array}{l}\text { Three daily } 5,000 \mathrm{U} \\
\text { rIL-2 doses }\end{array}$ & Day 7 \\
\hline
\end{tabular}

BALB/c mice were injected with three daily doses of 5,000 U rIL-2 (total dose 45,000 U over $3 \mathrm{~d}$ ) or excipient control buffer intraperitoneally on days $1-3$. Mice that were immunized subcutaneously with $\mathrm{J} 5$ antigen received the antigen only on day 1 . Sera were collected on day 7. For bacterial challenge studies, pretreated or immunized mice were inoculated with lethal doses of $E$. coli intraperitoneally on day 7 . Also, mice that received a booster immunization or treatments were given the J5 immunogen and/or the series of rIL-2 or excipient buffer control treatments on day 14 or days 14-16, respectively. Sera was again collected on day 21 and assessed for antibody levels.
Measurement of antibody responses. Antibody titers in sera were determined for pooled or individual serum preparations by a solid phase enzyme-linked immunosorbent assay (ELISA) as described previously (13). Briefly, $100 \mathrm{ng} / \mathrm{ml} \mathrm{J5} \mathrm{LPS} \mathrm{was} \mathrm{dissolved} \mathrm{in} \mathrm{sodium} \mathrm{carbonate} \mathrm{buffer,}$ supplemented with magnesium chloride, and coated onto microtiter plates (Dynatech Laboratories, Inc., Alexandria, VA) by overnight incubation at $4^{\circ} \mathrm{C}$. Remaining binding sites were saturated by bovine serum albumin (BSA). Plates were washed with phosphate-buffered saline (PBS) and 100 $\mu \mathrm{l}$ serum dilutions were added for $2 \mathrm{~h}$ at room temperature. After repeated washing with PBS, plates were incubated with isotype-specific peroxidasecoupled goat anti-mouse Ig (Cappel Laboratories, Cochranville, PA) for $2 \mathrm{~h}$. Goat anti-mouse IgM was used at a dilution of 1:750; goat antimouse IgG gave optimal results at a dilution of $1: 1,000$. The plates were washed again and peroxidase activity was measured by using $o$-phenylenediamine dihydrochloride at a concentration of $1 \mathrm{mg} / \mathrm{ml}$ and $\mathrm{H}_{2} \mathrm{O}_{2}$ as substrates in $0.1 \mathrm{M}$ citric acid, $\mathrm{pH}$ 4.5. The reaction was stopped with $100 \mu \mathrm{l} 2 \mathrm{M} \mathrm{H}_{2} \mathrm{SO}_{4}$. The optical density of each well was measured by a micro-ELISA reader at a wavelength of $480 \mathrm{~nm}$. Results were expressed as the mean ELISA units. All test samples were done in triplicate. The standard error of the mean was $<10 \%$ for each serum sample. To avoid variations due to interassay variability, sera of untreated and treated mice were always measured in the same ELISA assay. Also, total IgM and IgG amounts in pooled or individual mouse serum samples were measured by Rocket immunoelectrophoresis. Commercially available affinity-purified mouse IgM and IgG (Tago Inc., Burlingame, CA) and goat anti-mouse IgM and IgG (Tago Inc.) reagents were employed as standards and precipitating antibody preparations, respectively, in this assay.

Preparation of sera and IgM fractions for passive immunization experiments. Mice were immunized with $\mathrm{J} 5$ antigen and/or treated with rIL-2 or excipient buffer control as described. $5 \mathrm{~d}$ after termination of the initial treatment, sera were collected, pooled, and filtered through $0.45-\mu \mathrm{m}$ membranes. To purify IgM, pooled sera were absorbed with anti-IgM coupled to cyanogen bromide $(\mathrm{CnBr})$-activated Sepharose 4B beads (Pharmacia Fine Chemicais, Div. of Pharmacia Inc., Piscataway, $\mathrm{NJ}$ ). Isotype-specific goat anti-mouse IgM (Tago Inc.) was demonstrated not to be cross-reactive with mouse IgG in a direct ELISA. CnBr Sepharose 4B beads were activated with $1 \mathrm{mM} \mathrm{HCl}$ and immediately coupled with the antiserum in $0.1 \mathrm{M} \mathrm{NaHCO}_{3}$ and $0.5 \mathrm{M} \mathrm{NaCl}$ buffer, $\mathrm{pH}$ 8.3. To purify IgM, coupled beads were mixed with aliquots of pooled sera. The IgM-depleted serum fractions were separated by centrifugation from the IgM fraction bound to coupled beads. IgM antibodies were eluted from the beads with $\mathrm{KSCN}-\mathrm{Na}_{4} \mathrm{OH}$ buffer, $\mathrm{pH}$ 10.5. The IgM eluate was immediately neutralized and dialyzed against PBS. The IgM-depleted supernatants and IgM-containing eluates were pooled, respectively, filtersterilized by passage through $0.45-\mu \mathrm{m}$ membranes, and adjusted to the equivalent volume as the initial serum pool by adding PBS. The amount of IgM in the IgM fraction and in the depleted serum was determined in a direct ELISA on mouse anti-IgM-coated plates. Also, IgM and IgG titers to J5 antigen were measured in both fractions by ELISA. The protective efficacy of both fractions was assessed in passive immunization experiments. Naive BALB/c mice were injected with either $0.5 \mathrm{ml}$ purified IgM fractions or the IgM-depleted fractions $3 \mathrm{~h}$ before and at the time of the bacterial challenge. The sera were never heat-treated and were kept cold at $4^{\circ} \mathrm{C}$ during processing and storage.

\section{Results}

IgM antibodies to glycolipid core antigen J5 are induced after specific immunization and after treatment in vivo with rIL-2. Antibodies specific for the glycolipid core J5 antigen of Enterobactericeae appeared to have protective effects against gramnegative bacterial sepsis. To analyze humoral responsiveness of BALB/c mice to J5 antigen, we immunized animals subcutaneously with $50 \mu \mathrm{g}$ semi-soluble $\mathrm{J} 5$ antigen in the absence of adjuvants. To explore the possibility that exogenous rIL-2 could augment antibody production to J5 antigen, we treated one group 
of BALB/c mice with three daily doses of 5,000 U rIL-2 for $3 \mathrm{~d}$ (total dose 45,000 U rIL-2) after immunization. Mice were boosted with $\mathrm{J} 5$ antigen after $2 \mathrm{wk}$ and again received three daily injections with 5,000 U rIL-2 over three consecutive days (total dose 45,000 U rIL-2). Treatment with rIL-2 in the absence of any antigen or adjuvant was sufficient to induce significant levels of anti-J5 IgM-specific for J5 antigen in the sera of treated mice. Concentrations of rIL-2-induced IgM antibodies were similar to J5 IgM-specific ELISA titers in J5 immunized mice (Fig. 1). Addition of rIL-2 to the J5 antigen immunization protocol enhanced the primary IgM anti-J5 response at day 7, but did not further increase IgM titers during the secondary response when compared with the effect of rIL-2 or J5 alone. From the same sera, IgG antibodies specific for J5 were determined. As shown in Fig. 1, rIL-2 alone did not induce production of any J5-specific IgG antibodies during either the primary or secondary response. The primary humoral response to J5 immunization was limited to antibodies of the IgM subclass. However, boosting with the glycolipid core J5 antigen caused the production of high titers of IgG anti-J5 antibodies that was not further increased by additional treatment with rIL-2 (Fig. 1). The effect of rIL-2 to induce IgM antibodies after injection in vivo was not selective for an anti-J5 response. As we have recently reported (9), sera of rIL-2-treated mice contain IgM antibodies against multiple antigens (e.g., keyhole limpet hemocyanin, sperm whale myoglobin, or ovalbumin) despite no prior direct immunization with these antigens. Thus, anti-J5 antibodies are included among the polyclonal IgM antibodies produced after rIL-2 administration. Sera from the primary response to rIL-2 contained on the average

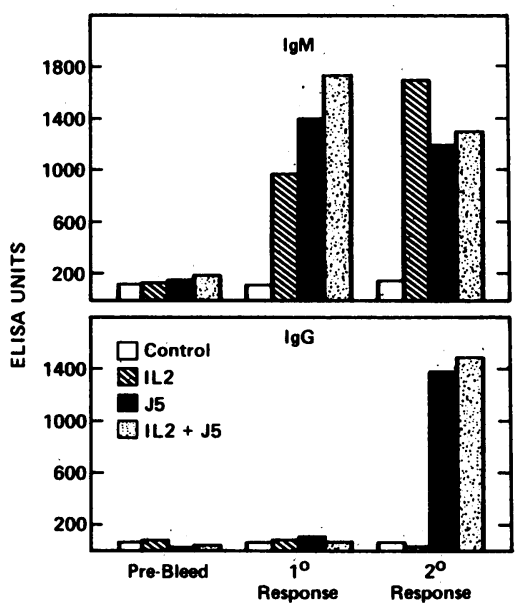

Figure 1. Humoral responses to immunization with $\mathrm{J} 5$ antigen and/or administration in vivo of rIL-2. BALB/ c mice $(n=10$ mice/ group) were either immunized with $50 \mu \mathrm{g}$ semi-soluble $\mathrm{J} 5$ antigen or were injected with a total dose of $45,000 \mathrm{U}$ rIL-2. The lymphokine was given without adjuvanits in three divided doses of $5,000 \mathrm{U} / \mathrm{d}$ during the $3 \mathrm{~d}$ after immunization. One cohort ( $n$ $=10$ mice) of mice received $\mathrm{J} 5$ immunization before the rIL-2 treatment. Control mice $(n$ $=10$ mice) were injected with excipient control buffer instead of rIL2. To induce a secondary response, antigen injections were repeated similarly beginning on day 14 . Mice treated with the combination of $\mathrm{J} 5$ and rIL-2, and mice that had received rIL-2 alone in the absence of any other antigen in the primary response, were again injected with rIL-2 on days 14-16. Sera were collected on day 7 and day 21 , respectively. IgM titers specific for J5 antigen (top) and IgG anti-J5 titers (bottom) were measured on pooled serum samples in a solid phase ELISA with J5 coupled plates. The specific anti-J5 IgM ELISA titers of the primary and secondary responses were significantly different $(P$ $<0.05$ ) in mice treated with rIL-2, J5 antigen alone, or rIL-2 plus J5 antigen than in mice treated with excipient control buffer. Specific anti-J5 IgG ELISA titers were significantly different $(P<0.05)$ for mice treated with J5 and J5 plus IL-2 during the secondary response than the other groups. fivefold greater total amounts of IgM than that from the primary response to $\mathrm{J} 5$ antigen or normal sera, as determined by Rocket immunoelectrophoresis (data not shown). Boosting with rIL-2 did not produce enhanced IgM production; also, rIL-2 treatment did not augment IgG humoral responses.

Mouse model of acute gram-negative septicemia. To evaluate protective effects of anti-J5 or rIL-2-induced IgM antibodies in systemic gram-negative bacterial infections, we established an animal model for $E$. coli septicemia. BALB/c mice were injected intraperitoneally with increasing doses of $E$. coli strain J96. Lethal bacterial doses caused the death of normal nontreated (naive) mice within 14 to $18 \mathrm{~h}$ after intraperitoneal injection. A doseresponse curve for normal mice was determined and ranged between an $\mathrm{LD}_{0}$ of $6 \times 10^{7}$ and an $\mathrm{LD}_{100}$ of $1 \times 10^{9}$ bacteria (Fig. 2). Infection with calibrated doses of bacteria that were estimated to be lethal for $50 \%$ of the naive mice were usually used to compare directly the efficacy of different modes of pretreatment or immunization. To control for interexperimental variability, untreated and treated animals were always tested within the same experiment. In another set of experiments, 10 mice that received intraperitoneally $10^{8} \mathrm{E}$. coli strain $\mathrm{J} 96 \mathrm{had}$ 50-75 $\mu \mathrm{l}$ of blood cultured in trypticase soy broth every $2 \mathrm{~h}$ until death or $18 \mathrm{~h}$ after the intraperitoneal injection. Mice that survived had additional blood cultures at 24 and $48 \mathrm{~h}$ after the intraperitoneal injection. Results of blood cultures for $E$. coli strain J96 (12) indicated that all mice had $E$. coli bacteremia by the 6th $\mathrm{h}$ after intraperitoneal injection, which persisted for the next $12 \mathrm{~h}$ or until death. Among mice that survived the primary intraperitoneal injection, blood cultures were negative at 24 and $48 \mathrm{~h}$.

Protection from septic death from $E$. coli infection by pretreatment with $r I L-2$ or preimmunization with $J 5$. To evaluate the efficacy of pretreatment with either J5, rIL-2, or the combination of both to prevent death from systemic gram-negative infection, we infected mice $7 \mathrm{~d}$ after the respective initial treatment with doses of $E$. coli that were sufficient to cause the death of $50 \%$ of the control animals. When survival rates of the different groups were compared, J5 immunization slightly protected mice

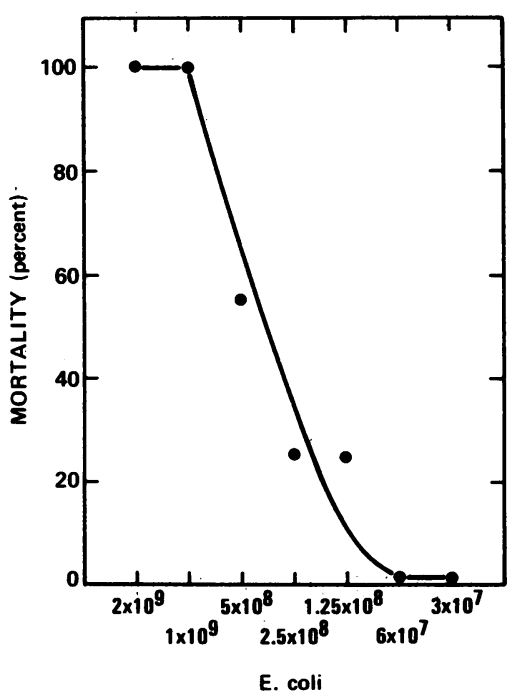

Figure 2. Dose-response curve for acute $E$. coli septicemia after intraperitoneal bacterial challenges. $B A L B / c$ mice $(18-20 \mathrm{~g}$ body $\mathrm{wt})$ were infected with increasing doses of $E$. coli strain J96. Bacteria were injected intraperitoneally through a 27-gauge needle. Each point on the graph represents the overall mortality of 10 to 14 mice that were given a specific bacterial dose $24 \mathrm{~h}$ after the bacterial challenge. Mice were observed every 2-4 $h$ for the first day and every $6 \mathrm{~h}$ for $5 \mathrm{~d}$ after infection. Death occurred between 14 and $18 \mathrm{~h}$ after bacterial challenges. A total of 78 naive mice was used to establish the dose-response relationship. 
(Table II): $67 \%$ survived compared with $47 \%$ of the control group. Significant protection $(P<0.025)$ was achieved with the administration of rIL-2 alone in vivo 1 wk before the bacterial challenge: $80 \%$ of IL-2-treated animals survived infection with lethal doses of $E$. coli. The most significant protective effect against lethal challenges with $E$. coli was induced by co-administration of the glycolipid core J5 antigen and rIL-2. $86 \%$ of animals pretreated with the combination of J5 and rIL-2 survived intraperitoneal challenges with doses of $E$. coli that were able to kill 53\% of the control mice (Table II).

The protective capacity of rIL-2 and J5 immunization can be transferred by serum of pretreated animals. Passive immunization experiments were designed to explore the possibility that factors in sera of rIL-2 injected animals were protective against the fatal outcome of $E$. coli septicemia. BALB/c mice were treated with a total of $45,000 \mathrm{U}$ rIL-2 given as three 5,000 $\mathrm{U}$ daily doses on three consecutive days and sera were collected $4 \mathrm{~d}$ after termination of the rIL-2 treatment. Control animals received excipient control buffer solution instead of rIL-2. 0.5 $\mathrm{ml}$ pooled serum was injected intraperitoneally into recipient mice $3 \mathrm{~h}$ before and again at the time of the challenge with an inoculum of $E$. coli that was equal to three times the $\mathrm{LD}_{50} .20 \%$ of the mice passively immunized with $1 \mathrm{ml}$ of control mouse serum survived this bacterial infection, whereas $100 \%$ of mice that had received $1 \mathrm{ml}$ of serum from rIL-2-treated mice survived this infectious challenge (Table III). In another set of experiments to determine the protective capacity of passively transferred sera in mice that subsequently received $\mathrm{LD}_{100}$ doses of $E$. coli, we injected mice intraperitoneally with sera obtained from the following groups: (1) rIL-2-treated mice, (2) J5 antigen-immunized mice, (3) mice that had been immunized with $\mathrm{J} 5$ antigen and treated with rIL-2, or (4) control buffer-treated mice, all as described in Table I. Sera were collected $7 \mathrm{~d}$ after the start of treatment or immunization protocols. IL-2-treated and/or J5-immunized mice contained only IgM, but no IgG that was specific for $\mathrm{J} 5$ antigen as determined by ELISA. Passive immunization with sera from J5-immunized or rIL-2-treated mice was able to temporarily postpone the lethal effects of bacterial infection (Fig.

Table II. Protection from Septic Death after E. coli Infection by Pretreatment with Recombinant IL-2 and/or J5 Antigen

\begin{tabular}{lll}
\hline Treatment group & Survival rate & $P$ value* \\
\hline & No. alive/total (\%) & \\
Control buffer & $14 / 30(47)$ & - \\
J5 antigen & $20 / 30(67)$ & $>0.5$ \\
rIL-2 & $24 / 30(80)$ & $<0.025$ \\
rIL-2 plus J5 antigen & $25 / 29(86)$ & $<0.001$ \\
\hline
\end{tabular}

Treatment groups included mice treated with excipient buffer control, $50 \mu$ g s.c. $E$. coli strain J5 antigen, a total of 45,000 U s.c. rIL-2 alone, or J5 antigen plus $45,000 \mathrm{U}$ s.c. rIL-2. Details of the immunizational and treatment protocol are described in the text and in Table I. $7 \mathrm{~d}$ after the initial immunization or treatments, mice were challenged with an intraperitoneal bacterial inoculum of $E$. coli strain J96. Mice were assessed for survival over the next $5 \mathrm{~d}$. Significant differences between the control buffer treatment groups and each of the experimental treatment groups were analyzed.

* $P$ value calculated by $\chi^{2}$-test with Yates' corrections between the control buffer treatment group and each of the experimental treatment groups.
Table III. rIL-2-induced Protective Effect Can Be Transferred by Serum

\begin{tabular}{lcl}
\hline Passive immunization & Survival rate $(24 \mathrm{~h})$ & $P$ value* \\
\hline & No. alive/total $(\%)$ & \\
Control serum & $2 / 10(20)$ & - \\
Serum from rlL-2-treated mice & $10 / 10(100)$ & $<0.01$ \\
\hline
\end{tabular}

BALB/c mice were treated with rIL-2 or buffer control as described in Table I. On day 7, they were killed and serum was collected. Naive BALB/c mice were injected with $0.5 \mathrm{ml}$ of pooled serum $3 \mathrm{~h}$ before and at the time of the bacterial challenge with three times the $L_{50}$ inoculum of $E$. coli for naive mice. Therefore, BALB/c mice treated with normal mouse serum required a three times higher $\mathrm{LD}_{50}$ than saline-treated naive mice.

* $P$ value calculated $\chi^{2}$ test with Yates' corrections between the groups.

3). When these sera were given $3 \mathrm{~h}$ before and at the time of subsequent lethal $E$. coli injection, a greater number of mice survived at $14-18 \mathrm{~h}$ after the bacterial challenge $(P<0.05)$ than mice that received serum from buffer control-treated mice. By $24 \mathrm{~h}$ after the bacterial challenge, there was no difference in survival among mice that received different serum preparations.

The IgM fraction in sera of rIL-2-treated mice has protective activities against death from gram-negative septicemia. The efficacy of injected rIL-2 in preventing death from gram-negative bacteremia correlated with the induction of a humoral IgM immune response. The J5-specific IgM ELISA titers in protective sera ranged between 1:3 and 1:10, with the mean at 1:6. This intriguing correlation between the induction of IgM antibodies and the prevention of death from bacteremia may suggest that IgM antibodies represented at least one of the protective serum fractions. To explore this possibility and to identify serum factors

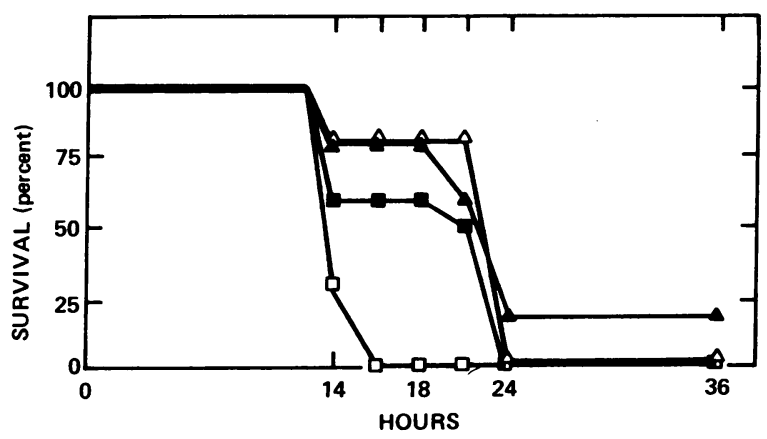

Figure 3. Sera of mice pretreated with $\mathrm{J} 5$ and/or rIL-2 are protective in passive immunization experiments. BALB/c mice ( $n=10 /$ group) were treated with control buffer or rIL-2, or were immunized with J5 and then treated with control buffer or rIL-2 as described in Table I. Sera were collected on day 7 , pooled, filtered, and $0.5-\mathrm{ml}$ aliquots were transferred into naive recipient BALB/c mice by an intraperitoneal injection. Recipient mice were challenged with intraperitoneal in ocula of $E$. coli $3 \mathrm{~h}$ later together with a second dose of $0.5 \mathrm{ml}$ serum. Each point on the figure represents the overall survival of 10 mice per group at the different time points after the $\mathrm{LD}_{100} E$. coli injection. Mice received serum from either control buffer treatment ( $(\square)$, rIL-2 treatment ( $\square$ ), J5 immunization ( $\triangle$ ), or J5 immunization plus rIL-2 treatment $(\Delta)$. Animals were observed for septic death every $2-4$ h until $36 \mathrm{~h}$ after intraperitoneal injection. No more subsequent deaths occurred over the next $4 \mathrm{~d}$ among mice that survived $36 \mathrm{~h}$. 
responsible for the protective effect, we isolated IgM antibodies from sera of animals that had been initially treated with rIL-2 or excipient control buffer $7 \mathrm{~d}$ before, and assessed the efficacy of the affinity-purified IgM fraction and the IgM-depleted serum fraction in preventing septic death in mice. Different sources of polyclonal goat-antisera with specificity for mouse IgM were tested for their cross-reactivity with antibodies of other subclasses. To perform affinity purification, one batch of highly specific goat anti-mouse IgM was selected and coupled to $\mathrm{CnBr}$ Sepharose $4 \mathrm{~B}$ beads. IgM was purified from the sera of treated mice by multiple absorption steps with the anti-IgM coupled beads. Total IgM and IgM titers specific for J5 in the affinity-purified fraction as well as in the IgM-depleted fraction were measured by an ELISA system. The IgM-depleted serum fraction was completely devoid of IgM antibodies (data not shown). Sera of rIL-2-treated animals contained about fivefold higher IgM concentrations than that of control animals. The affinity-purified IgM and the IgM-depleted serum fractions were adjusted to volume equivalents of the original sera. Recipient animals were passively immunized with $0.5 \mathrm{ml} 3 \mathrm{~h}$ before and again at the time of infection with $E$. coli. All animals that had received the IgM fraction of rIL-2-treated sera survived intraperitoneally administered $\mathrm{LD}_{80}$ doses of $E$. coli (Fig. 4). The IgM preparation from sera of control animals had lesser protective capacity; mor-

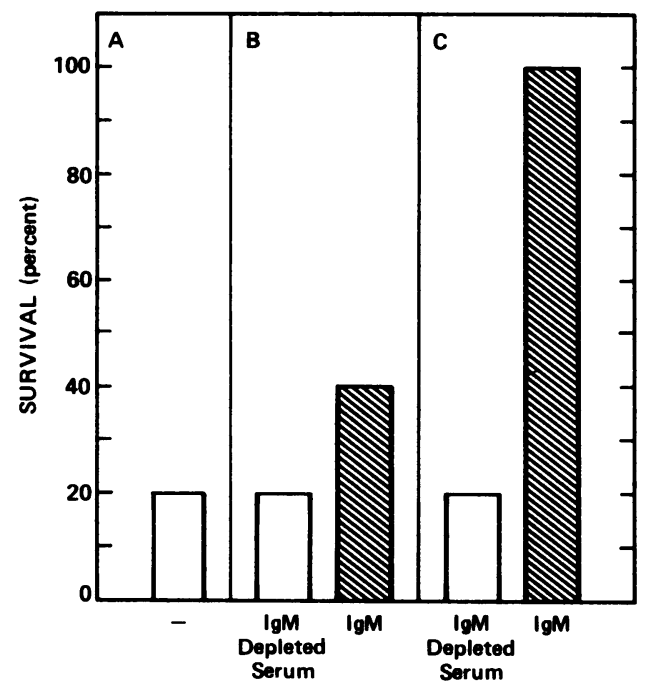

Figure 4. IgM induced by administration in vivo of rIL-2 protects mice from septic death. BALB/c mice ( $n=15-20$ mice/group) were treated with a total of $45,000 \mathrm{U}$ rIL-2 over $3 \mathrm{~d}$ or with excipient control buffer. Sera were harvested on day 7. IgM was purified by affinity absorption to anti-IgM coupled beads. The IgM fraction and the IgMdepleted serum fraction were adjusted to volume equivalents compared with their original serum pool. These fractions were transferred into naive BALB/c mice by injecting a $0.5-\mathrm{ml}$ aliquot $3 \mathrm{~h}$ before and at the time of bacterial challenge. $(A)$ Subsequent survival after $24 \mathrm{~h}$ of 15 naive mice that received an $\mathrm{LD}_{80} E$. coli injection alone; $(B)$ subsequent survival of 15 mice that received IgM-depleted serum and 15 mice that received affinity-purified IgM from mice previously treated with excipient control buffer after an $\mathrm{LD}_{80}$ of $E$. coli; and $(C)$ subsequent survival of 15 mice that received IgM-depleted serum and 15 mice that received affinity-purified IgM from mice previously treated with rIL-2 after an $\mathrm{LD}_{80}$ of $E$. coli. Results indicate that the IgM fraction of rIL-2-treated mice protected mice significantly $(P<0.05)$ from fatal $E$. coli infection when compared with the IgM-depleted fraction of rlL-2 treated mice. tality rates were decreased from 80 to $60 \%$. IgM-depleted sera of rIL-2-treated or control buffer-treated BALB/c mice did not transfer immunity to recipient animals. Thus, IgM was necessary and sufficient to provide protection in this model.

Efficacy of treatment with rIL-2 and/or immunization with $J 5$ antigen to prevent septic death in mice infected with repeated doses of bacteria. The efficacy of rIL-2 in vivo was evaluated in an infection model wherein a sublethal dose of $E$. coli was followed by twice the lethal dose $24 \mathrm{~h}$ later. This model might be more representative of systemic bacterial infections. Groups of BALB/c mice were pretreated with rIL-2 in vivo with a total of $45,000 \mathrm{U}$ over $3 \mathrm{~d}$ and/or immunized once with $50 \mu \mathrm{g}$ of J5 antigen. $7 \mathrm{~d}$ later, they were intraperitoneally injected with a low dose of $E$. coli that caused the death of only $17 \%$ of control animals after $24 \mathrm{~h}$ (Table IV). At that time, the animals received a second dose of bacteria that was twice the $\mathrm{LD}_{100}$. Only 1 of 19 remaining animals $(5 \%)$ in the control group could sustain the repeated bacterial challenge. Mice that were preimmunized with $\mathrm{J} 5$ antigen and/or pretreated with rIL-2, however, were all able to survive the second $E$. coli intraperitoneal dose that was twice the $\mathrm{LD}_{100} .67 \%$ of $\mathrm{J} 5$ immunized animals survived the second intraperitoneal challenge with the very high doses of $E$. coli (Table IV); $50 \%$ of the rIL-2-treated mice survived the repeated $E$. coli dose. Optimal protection was again achieved when rIL-2 and J5 antigen were combined in the pretreatment protocol. Only 4 out of these 25 mice that received a second dose of twice the $\mathrm{LD}_{100}$ died. It is interesting to note in the progress of this study that recent exposure of mice to a sublethal dose of $E$. coli induced a host response that protected the majority of the previously naive animals from acute septic death when subsequently infected with a single $\mathrm{LD}_{100}$ dose (data not shown). At least twice the lethal dose of $E$. coli had to be injected to cause septic death in naive mice that had previously (1 day earlier) received sublethal doses of bacteria. However, under these circumstances, the prior administration of $\mathrm{J} 5$ antigen and/or rIL-2 protected BALB/c mice from septic death.

\section{Discussion}

Numerous reports have established that preimmunization with the glycolipid core J5 antigen of Enterobactericeae or passively transferred anti-J5 and anti-LPS antibodies provide protection against the fatal sequelae of gram-negative septicemia in a number of experimental animal models and humans. The significant finding of this study is that when rIL-2 was given systemically without any adjuvants, it could substitute for this bacterial core endotoxin antigen or LPS and it was highly effective in protecting animals from septic death after $E$. coli infection. Although the mechanism of the protection has not been completely clarified, there is a striking correlation between the ability of $\mathrm{J} 5$ antigen or rIL-2 to induce IgM antibodies specific for the LPS core J5 antigen and the protective efficacy of both agents. In passive immunization studies, we demonstrated that the protection of the host was mediated by affinity-purified antibodies of the IgM subclass. In comparison with the IgM-depleted fraction of the same serum at equivalent doses, we demonstrated that IgM was necessary and sufficient to protect against lethal $E$. coli sepsis. However, the possibility exists that during the processing of sera, additional protective humoral components in the nonimmunoglobulin fractions, e.g., acute-phase reactants, may have been destroyed. Our data do suggest that IgM antibodies directed 
Table IV. Protective Effect of Pretreatment with Recombinant IL-2 and/or J5 Immunization in Mice Infected Repeatedly with E. coli

\begin{tabular}{lllll}
\hline Treatment group & Survival rate $(24 \mathrm{~h})$ & $P$ value & Survival rate $(96 \mathrm{~h})$ & $P$ Nalue* \\
\hline & No. alive/total $(\%)$ & & $1 / 19(5)$ & - \\
Buffer control & $19 / 26(73)$ & - & $16 / 24(67)$ & $<0.001$ \\
J5 antigen & $24 / 24(100)$ & $<0.05$ & $12 / 24(50)$ & $<0.001$ \\
rIL-2 & $24 / 24(100)$ & $<0.05$ & $21 / 25(84)$ & $<0.001$ \\
rIL-2 plus J5 antigen & $25 / 25(100)$ & $<0.05$ & & \\
& & & & \\
\hline
\end{tabular}

BALB/c mice were immunized with J5 and treated with rIL-2 (45,000 U rIL-2 over $3 \mathrm{~d})$ as described in Table I. $7 \mathrm{~d}$ after immunization or the initiation of the rIL-2 treatment, mice were infected with a sublethal dose of $E$. coli intraperitoneally. Surviving mice were challenged with $2 \times 10^{9}$ E. coli $\left(2 \times \mathrm{LD}_{100}\right) 24 \mathrm{~h}$ later. Survival was monitored for the following $7 \mathrm{~d}$. No mice died after $48 \mathrm{~h}$ after the second bacterial administration. * $P$ value calculated by $\chi^{2}$ test with Yates' correction between the buffer control group and each of the experimental treatment groups after each bacterial challenge.

against antigenically similar cell wall components of gram-negative rods like the $\mathrm{J} 5$ antigen may have provided resistance to infections by a broad spectrum of Enterobactericeae microorganisms. Due to the polyclonal nature of the IgM response, we suggest that antibodies against other microorganisms might be demonstrated and might also confer specific protection in this model.

Stimulation of protective immunity against gram-negative organisms has been of increasing interest. Polyclonal antisera raised by immunization with smooth bacteria (4-8) have been successfully used to passively transfer immunity against homologous organisms. Also monoclonal antibodies against $\mathrm{O}-$ side-chain LPS determinants (14-16) have been shown to have protective capacity in an in vivo bacterial challenge model. However, the usefulness of antisera for passive immunotherapy in gram-negative bacterial systemic infections has been hampered by the vast heterogeneity found among strains of gram-negative organisms. Therapeutically useful reagents require cross-reactivity of the antisera with a broad spectrum of bacteria of the Enterobactericeae. For these reasons rough mutants of gramnegative bacteria, like $E$. coli strain $\mathrm{J} 5$, have been used for immunization. The mutants lack the heterogeneous polysaccharide $O$ antigen but express the conserved core of the LPS molecule (17). Conflicting data have been reported about the protective capacity of these cross-reactive antisera. In several studies, animals could be protected from experimentally induced bacteremias. As Ziegler et al. showed, human antisera that is prepared by vaccination of healthy men with $E$. coli $\mathrm{J} 5$ antigen can confer protection from death to bacteremic patients (8). However, a panel of monoclonal antibodies specific for $E$. coli J5 LPS did not have any protective effect in a lethal LPS challenge assay nor in a bacterial challenge model (18). We report here that immunization with $\mathrm{J} 5$ antigen induced a primary IgM response and a secondary IgM and IgG response. When animals were preimmunized with $\mathrm{J} 5$ antigen, they acquired protection against lethal intraperitoneal infection with $E$. coli during their primary IgM response. We suggest that IgM anti-J5 is sufficient to provide protection against death from gram-negative bacteremia.

Surprisingly, rIL-2, when injected in divided doses 4-7 d before a lethal $E$. coli infectious challenge, was at least as efficient as $\mathrm{J} 5$ antigen immunization in inducing protective immunity. It has been recently shown that treatment of mice with rIL-2 without adjuvants results in a polyclonal IgM response (9) and increases total IgM serum levels about fivefold. We have not seen any effect on serum concentrations of IgG after adminis- tration of rIL-2 in this study. The mechanism of action of systemically administered rIL-2 in the induction of polyclonal IgM is not yet clear. Analysis of antigen-specific precursor frequencies of proliferative $T$ cells showed that injection of rIL-2 is followed by a polyclonal $T$ cell activation (9). The finding that the polyclonal IgM response could be induced in helper $\mathrm{T}$ cell-depleted mice and in nude mice suggested as one possibility that rIL-2 might have a direct effect on the B cell compartment. Receptor molecules for IL-2 have been found on a subset of B cell, Lyt ${ }^{+}$ B cells (9). Antibody responses of that B cell subset are limited to antibodies of the IgM subclass $(19,20)$. Antibody specificities induced by rIL-2 included IgM antibodies against $\mathrm{J} 5$ antigen (Fig. 1). When the IgM fraction of sera of rIL-2-treated animals was purified by affinity absorption and transferred into naive mouse recipients, the protective efficacy was conferred only by the IgM fraction, not the remaining IgM-depleted serum fraction (Fig. 4). This suggests that IgM antibodies represent at least one of possibly many protective humoral factors against gram-negative bacterial infections. Protection efficacy against sequelae of gram-negative bacteremia has been described in preimmune rabbit sera (21). It is likely that this antibacterial immune activity was mediated by spontaneously produced IgM as is demonstrated in our model wherein some protection was provided by affinitypurified IgM from "normal" mice (Fig. 4). We believe that such naturally occurring IgM may have resulted from the action of endogenous IL- 2 that was secreted by helper $T$ cells in response to environmental antigens in the normal immune response. This action of the immune system may have given rise to the pool of circulating polyclonal IgM antibodies to microbial antigens that were observed in serum of "normal" animals without recent infection.

Experiments reported here did not address the question of how IgM antibodies elicited their protective capacities. Antibodies of the IgM subclass are not opsonic in themselves, but they can interact with a third component of complement, $\mathrm{C} 3 \mathrm{~b}$. Phagocytic cells expressing specific $\mathrm{C} 3 \mathrm{~b}$ receptors can then ingest and digest bacteria. Alternatively, IgM antibodies are very effective in binding complement and activating the complement cascade that leads to complement-mediated lysis of infective organisms. However, it is possible that the protective effect of J5 and rIL-2-induced IgM antibodies represented a neutralizing capacity for secreted endotoxins. Detoxification of LPS by antibodies probably provided an effective way for protection against pathogenicity of gram-negative sepsis.

The protective effect of rIL-2 pretreatment and J5 immu- 
nization was maintained in mice that received repeated doses of intraperitoneal bacterial inocula. When animals are initially exposed to sublethal doses of LPS, they develop a state of refractoriness to subsequent challenges with LPS or live gramnegative bacteria (22-25). Overwhelming doses (twice $\mathrm{LD}_{100}$ ) of $E$. coli bacteria were necessary to cause fatal septicemia in such mice with early phase endotoxin tolerance (Table IV). Nevertheless, pretreatment with rIL-2 was effective in protecting repeatedly infected animals from septic death. The efficacy of rIL2 protection in mice with early phase LPS tolerance provides evidence that rIL-2 does not represent an LPS-like tolerogen but rather induces protective host immunity by a mechanism different from hyporesponsiveness to LPS.

The lymphokine preparation used in the experiments described here is a recombinant product and has been produced in E. coli. One could argue that miniscule amounts of LPS $(<1$ pg per IL-2 injection measured in a Limulus assay) were contaminating the IL-2 preparation; however, it did not induce a secondary IgG response to LPS determinants when mice were immunized with rIL-2 and challenged with the same preparation (Fig. 1). In the same experiment, mice injected with $50 \mu \mathrm{g} \mathrm{J5}$ produced high serum IgG titers during the secondary response. Amounts of $10 \mathrm{ng} /$ mouse are usually considered as biologically active doses of LPS. Since the effect of J5 and rIL-2 was additive, contamination of the lymphokine solution with at most picogram amounts of LPS did not seem to relate to endotoxin biological activities. Finally, we have measured induction of bromelin plaques in spleen cells of J5 and LPS-treated and rIL-2-treated mice, which is a very sensitive assay system for in vivo LPS effects. rIL-2 equivalent to $10^{6} \mathrm{U}$ did not increase the numbers of plaque-forming cells (data not shown).

rIL-2 has been applied in patients with stage IV tumors and has been tolerated $(26,27)$. This, coupled with the finding that rIL-2 is more efficient than a glycolipid core antigen in inducing a protective humoral immune response, makes this lymphokine a suitable candidate for clinical application. In contrast to specific bacterial antigens, the stimulating effect of rIL-2 in protective immunity is polyclonal in nature and should not be hampered by the heterogeneity among members of the Enterobactericeae family. rIL-2 administration alone did not result in the production of IgG antibodies and did not induce immunologic memory. The protective efficacy seemed to be limited to 1 to 2 wk after termination of rIL-2 administration. We have previously shown that rIL-2 is effective in helper T cell-depleted mice. Thus, the polyclonal activation of IgM-producing B cells was not dependent on a fully competent immune system. The possibility in bacterial infections that IL-2 can stimulate other protective arms of immunity, e.g., cytotoxic $\mathrm{T}$ cells and elaboration of acute phase reactants, is now being evaluated. Also, the optimal doses and the kinetics of IL-2-induced immunity demonstrated in this report are being now studied in mice. It should be noted that the amount of rIL-2 necessary to induce antibody responses in mice would cause endothelial damage in humans if administered parenterally in equivalent amounts per body mass. It is well-known that large amounts of IL-2 administered to humans can cause a capillary leak syndrome. Therefore, instead of evaluating the IL-2 dose humoral responses in mice, a more direct method of determining the IL-2 dose required for humoral responses in humans may entail evaluation in nonhuman primates or humans. In conclusion, the possibility that rIL-2 might be a potential immunoprophylaxis reagent for individuals who develop predictable therapy-induced immunological deficiencies and carry a high risk for gram-negative bacterial septicemias has important clinical implications.

\section{Acknowledgments}

The authors would like to thank Cetus Corp., Emeryville, CA for their support and the gift of rIL-2. We also want to thank Kathleen Johnson for her technical help, and Diane Bet and Robyn Kizer for their excellent secretarial assistance in the preparation of this manuscript.

This manuscript was supported by the American Cancer Society grant 2 HLH 616, AI 18716, and the California Acquired Immunodeficiency Syndrome grant. Drs. Goronzy and Weyand are supported by the Juvenile Diabetes Foundation and the Arthritis Foundation, respectively.

\section{References}

1. Finland, M. 1980. Changing ecology of bacterial infections as related to antibacterial therapy. J. Infect. Dis. 122:419-431.

2. Myerowitz, R. L., A. A. Medeiros, and T. F. O'Brien. 1971. Recent experience with bacteremia due to gram-negative organisms. J. Infect. Dis. 124:239-246.

3. Berry, L. J. 1977. Bacterial toxins. Crit. Rev. Toxicol. 5:239-318.

4. Braude, A. I., and H. Douglas. 1972. Passive immunization against the local Schwartzman reaction. J. Immunol. 108:505-512.

5. Davis, C. E., E. J. Ziegler, and K. Arnold. 1978. Neutralization of meningococcal endotoxin by antibody to core glycolipid. J. Exp. Med. 147:1007-1017.

6. Marks, M. I., E. J. Ziegler, H. Douglas, L. B. Corbeil, and A. I. Braude. 1982. Induction of immunity against Haemophilus influenzae type B infection by Escherichia coli core lipopolysaccharide. J. Clin. Invest. 69:742-749.

7. Ziegler, E. J., H. Douglas, J. E. Sherman, C. E. Davis, and A. I. Braude. 1973. Treatment of E. coli and Klebsiella bacteremia in agranulocytic animals with antiserum to a UDP-Gal epimerase-deficient mutant. J. Immunol. 111:433-438.

8. Ziegler, E. J., J. A. McCutchan, J. Fierer, M. P. Glauser, J. C. Sadoff, H. Douglas, and A. I. Braude. 1982. Treatment of gram-negative bacteremia and shock with human antiserum to a mutant of Escherichia coli. N. Engl. J. Med. 307:1225-1230.

9. Weyand, C. M., J. Goronzy, M. J. Dallman, and C. G. Fathman. 1986. Administration of recombinant interleukin-2 in vivo induces a polyclonal IgM response. J. Exp. Med. 163:1607-1612.

10. Rosenberg, S. A., E. A. Grimm, M. McGrogan, M. Doyle, E. Kawasaki, K. Koths, and D. F. Mark. 1984. Biological activity of recombinant human interleukin-2 produced in Escherichia coli. Science (Wash. DC). 223:1412-1415.

11. Galanos, C., O. Luderitz, and O. Westphal. 1969. A new method for the extraction of R lipopolysaccharides. Eur. J. Biochem. 9:245-249.

12. O'Hanley, P., D. Lark, S. Falkow, and G. Schoolnik. 1985. Molecular basis of Escherichia coli colonization of the upper urinary tract in BALB/c mice: Gal-Gal pili immunization prevents Escherichia coli pyelonephritis in the BALB/c mouse model of human pyelonephritis. J. Clin. Invest. 75:347-360.

13. Shigeta, M., S. Takahara, S. J. Knox, T. Ishihara, E. S. Vitetta, and C. G. Fathman. 1986. Two independent pathways of helper activity provided by a single T cell clone. J. Immunol. 136:34-38.

14. Colwell, D. E., S. M. Michalek, D. E. Briles, E. Jirillo, and R. McGhee. 1984. Monoclonal antibodies to Salmonella lipopolysaccharide: anti- $O$-polysaccharide antibodies protect $\mathrm{C} 3 \mathrm{H}$ mice against challenge with virulent Salmonella typhimurium. J. Immunol. 133:950-957.

15. Kirkland, T. N., and E. J. Ziegler. 1984. An immunoprotective monoclonal antibody to lipopolysaccharide. J. Immunol. 132:2590-2592.

16. Kaufman, B. M., A. S. Cross, S. L. Futrovsky, H. F. Sidberry, and J. C. Sadoff. 1986. Monoclonal antibodies reactive with K1-encapsulated Escherichia coli lipopolysaccharide are opsonic and protect mice against lethal challenge. Infect. Immun. 52:617-619. 
17. Elbein, A. D., and E. C. Heath. 1965. The biosynthesis of cell wall lipopolysaccharide in Escherichia coli. 1. The biochemical properties of a uridine diphosphate galactose 4-epimeraseless mutant. J. Biol. Chem. 240:1919-1925.

18. Miner, K. M., C. L. Manyak, E. Williams, J. Jackson, M. Jewell, M. T. Gammon, C. Ehrenfreund, E. Hayes, L. T. Callahan, III, H. Zweerink, and N. H. Sigal. 1986. Characterization of murine monoclonal antibodies to Escherichia coli J5. Infect. Immun. 52:56-62.

19. Hayakawa, K., R. R. Hardy, M. Honda, L. A. Herzenberg, A. D. Steinberg, and L. A. Herzenberg. 1984. Ly-1 B cells: functionally distinct lymphocytes that secrete IgM antibodies. Proc. Natl. Acad. Sci. USA. 81:2494-2498.

20. Hayakawa, K., R. R. Hardy, L. A. Herzenberg, and L. A. Herzenberg. 1985. Progenitors for $L y-1$ B cells are distinct from progenitors for other B cells. J. Exp. Med. 161:1554-1568.

21. Greisman, S. E., E. J. Young, and D. DuBuy. 1973. Mechanisms of endotoxin tolerance. VIII. Specificity of serum transfer. J. Immunol. 111:1349-1360.

22. Greisman, S. E. 1983. Induction of endotoxin tolerance. In Beneficial Effects of Endotoxins. A. Nowotny, editor. Plenum Publishing Corp., New York. 149-178.

23. Williams, Z., C. F. Hertogs, and D. H. Pluznik. 1983. Use of mice tolerant to lipopolysaccharide to demonstrate requirement of cooperation between macrophages and lymphocytes to generate lipopolysaccharide-induced colony-stimulating factor in vivo. Infect. Immun. 41: $1-5$.

24. Madonna, G. S., and S. N. Vogel. 1985. Early endotoxin tolerance is associated with alterations in bone marrow-derived macrophage precursor pools. J. Immunol. 135:3763-3771.

25. Madonna G. S., J. E. Peterson, E. E. Ribi, and S. N. Vogel. 1986. Early-phase endotoxin tolerance: induction by a detoxified lipid A derivative, monophosphoryl lipid A. Infect. Immun. 52:6-11.

26. Rosenberg, S. A., M. T. Lotze, L. M. Muul, S. Leitman, A. E. Chang, S. E. Ettinghausen, Y. L. Matory, J. M. Skibber, E. Shiloni, J. T. Vetto, C. A. Seipp, C. Simpson, and C. M. Reichert. 1985. Observations on the systemic administration of autologous lymphokine-activated killer cells and recombinant interleukin-2 to patients with metastatic cancer. N. Engl. J. Med. 313:1485-1492.

27. Lotze, M. T., Y. L. Matory, S. E. Ettinghausen, A. A. Rayner, S. O. Sharrow; C. A. Y. Seipp, M. C. Custer, and S. A. Rosenberg. 1985. In vivo administration of purified human interleukin-2. II. Half life, immunologic effects, and expansion of peripheral lymphoid cells in vivo with recombinant IL-2. J. Immunol. 2865-2875. 